\title{
THE KALMAN-YAKUBOVICH-POPOV INEQUALITY FOR PASSIVE DISCRETE TIME-INVARIANT SYSTEMS
}

\author{
YURY ARLINSKII
}

Abstract. We consider the Kalman - Yakubovich - Popov (KYP) inequality

$$
\left(\begin{array}{cc}
X-A^{*} X A-C^{*} C & -A^{*} X B-C^{*} D \\
-B^{*} X A-D^{*} C & I-B^{*} X B-D^{*} D
\end{array}\right) \geqslant 0
$$

for contractive operator matrices $\left(\begin{array}{ll}A & B \\ C & D\end{array}\right):\left(\begin{array}{c}\mathfrak{H} \\ \mathfrak{M}\end{array}\right) \rightarrow\left(\begin{array}{c}\mathfrak{H} \\ \mathfrak{N}\end{array}\right)$, where $\mathfrak{H}, \mathfrak{M}$, and $\mathfrak{N}$ are separable Hilbert spaces. We restrict ourselves to the positive contractive solutions $X$. Using the parametrization of the blocks of contractive operator matrices, the Kreĭn shorted operator, and the Möbius representation of the Schur class operator-valued function we find several equivalent forms of the KYP inequality. The properties of solutions are established and it is proved that the minimal solution of the KYP inequality satisfies the corresponding algebraic Riccati equation and can be obtained by the iterative procedure with the special choice of the initial point. In terms of the Kreln shorted operators the necessary condition and some sufficient conditions for uniqueness of the solution are established.

Mathematics subject classification (2000): 47A48, 47A56, 47A63, 47A64, 93B28, 93B15, $94 \mathrm{C} 05$.

Key words and phrases: Passive system, transfer function, shorted operator, the Kalman - Yakubovich - Popov inequality, the Riccati equation.

\section{REFERENCES}

[1] W. N. ANDERSON, Shorted operators, SIAM J. Appl. Math., 20 (1971), 520-525.

[2] W. N. ANDERson And G. E. Trapp, Shorted operators, II, SIAM J. Appl. Math., 28 (1975), 60-71.

[3] W. N. Anderson And R. J. Duffin, Series and parallel addition of matrices, J. Math. Anal. Appl. 26 (1969), 576-594.

[4] T. ANDO, De Branges spaces and analytic operator functions, Lecture notes of the division of Applied Mathematics Research Institute of Applied Electricity, Hokkaido University, Sapporo, Japan, 1990.

[5] D. Z. ARov, Passive linear stationary dynamical systems, Sibirsk. Mat. Zh., 20 (1979), No.2, 211-228 [Russian]. English translation in Siberian Math. Journ., 20 (1979), 149-162.

[6] D. Z. AROV, Stable dissipative linear stationary dynamical scattering systems, Journal of Operator Theory, 1 (1979), 95-126 [Russian]. English translation in Interpolation Theory, Systems, Theory and Related Topics. The Harry Dym Anniversary Volume, Oper. Theory: Adv. Appl. 134 (2002), Birkhauser Verlag.

[7] D. Z. ARov, M. A. KaAshoeK, AND D. P. PIK, Minimal and optimal linear discrete time-invariant dissipative scattering systems, Integr. Equat. Oper. Theory, 29 (1997), 127-154.

[8] D. Z. Arov, M. A. KAASHOEK, AND D. P. PIK, The Kalman - Yakubovich - Popov inequality for infinite dimensional discrete time dissipative system, J. Operator Theory, 55 (2006), No.2, 393-438.

[9] D. Z. AROV, M. A. KAASHOEK, AND D. P. PIK, Minimal representations of a contractive operator as a product of two bounded operators, Acta Sci. Math. (Szeged), 71 (2005), 313-336.

[10] D. Z. AROV AND M. A. NUDEL'MAN, A criterion for the unitarily similarity of minimal passive systems of scattering with a given transfer function, Ukrain. Mat. Zh. 52 (2000), No.2, 161-172, [Russian]. English translation in Ukrainian Math. Journ., 52 (2000), No.2,161-172. 
[11] D. Z. AROV AND M. A. NUDEL'MAN, Tests for the similarity of all minimal passive realizations of a fixed transfer function (scattering or resistance matrix), Mathematicskiu Sbornik, 193 (2002), No.6, 3-24, [Russian]. English translation in Sbornik: Mathematics, 193 (2002), No.6, 791-810

[12] D. Z. AROV AND O. J. STAFFANS, Bi-inner dilations and bi-stable passive scattering realizations of Schur class operator-valued functions (to appear in Int. Equat. Oper. Theory).

[13] GR. ARsene AND A. GHEONDEA, Completing matrix contractions, J. Operator Theory, 7 (1982), 179-189.

[14] M. BAKONYI AND T. CONSTANTINESCU, Schur's algorithm and several applications, Pitman Research Notes in Mathematics Series, v. 261, Longman Scientific and Technical, 1992.

[15] L. De Branges and J. RovnyaK, Square Summable Power Series, Holt, Rinehart and Winston, New-York, 1966.

[16] L. DE BRANGES AND J. RovNYAK, Appendix on square summable power series, Canonical models in quantum scattering theory, in: Perturbation Theory and its Applications in Quantum Mechanics, (ed. C. H. Wilcox), New-York, 1966, pp. 295-392.

[17] M. S. BRODSKIĬ, Unitary operator colligations and their characteristic functions, Uspekhi Mat. Nauk, 33 (1978), No.4, 141-168 [Russian]. English translation in Russian Math. Surveys, 33 (1978), No.4, 159-191.

[18] CH. DAVIS, W. M. KAHAN, AND H. F. WeINBERGER, Norm preserving dilations and their applications to optimal error bounds, SIAM J. Numer. Anal., 19 (1982), 445-469.

[19] R. G. Douglas, On majorization, factorization and range inclusion of operators in Hilbert space, Proc. Amer. Math. Soc. 17 (1966), 413-416.

[20] P. A. Fillmore AND J. P. Williams, On operator ranges. Advances in Math. 7 (1971), 254-281.

[21] T. KATO, Perturbation theory for linear operators, Springer-Verlag, Berlin, Heidelberg, 1995.

[22] M. G. KREIIN, Theory of selfadjoint extensions of semibounded operators and its applications.I, Mat. Sb., 20 (1947), No.3, 431-498. [Russian]

[23] M. G. KREIN AND I. E. OVChARENKO, On $Q$-functions and sc-extensions of nondensely defined Hermitian contractions, Sibirsk. Mat. Zh., 18 (1977), No.5, 1032-1056 [Russian]. English translation in Siberian Math. Journ, 18 (1977), No.5, 728-746.

[24] K. NISHIO AND T. ANDO, Characterizations of operators derived from network connections, J. Math. Anal. Appl. 53 (1976), 539-549.

[25] E. L. PEKAREV, Shorts of operators and some extremal problems, Acta Sci. Math. (Szeged) 56 (1992), $147-163$.

[26] A. C. RAN AND R. VREUGDENHIL, Existence and comparison theorems for algebraic Riccati equations for continuous and discrete-time systems, Linear Algebra and its Applications, 99 (1988), 63-83.

[27] Yu. L. SHMUL'YAN, Hellinger's operator integral, Mat. Sb. 49 (1959), No.4, 381-430. [Russian]

[28] YU. L. SHMUL'YAN, Generalized fractional-linear transformations of operator balls, Sibirsk. Mat. Zh. 21 (1980), No.5, 114-131 [Russian]. English translation in Siberian Mathematical Jour. 21 (1980), No.5, 728-740.

[29] YU. L. SHMUL'YAN, Certain stability properties for analytic operator-valued functions, Mat. Zametki 20 (1976), No.4, 511-520 [Russian]. English translation in Mathematical Notes, 20 (1976), No.4, 843-848.

[30] YU. L. SHMUL'YAN AND R. N. YANOVSKAYA, Blocks of a contractive operator matrix, Izv. Vuzov, Mat., 7 (1981), 72-75. [Russian]

[31] O. J. Staffans, Passive linear discrete time-invariant systems, Proceedings of the International Congress of Mathematicians, Madrid, Spain, 2006, European Mathematical Society, pp. 1367-1388.

[32] A. B. SHTRAUS, On one class of regular operator-functions, Doklady Akad. Nauk SSSR 70 (1950), No.4, 577-580. [Russian]

[33] B. SZ.-NAGY AND C. FoIAS, Harmonic analysis of operators on Hilbert space, North-Holland, New York, 1970. 